\title{
Indirect Vector Control of Induction Motor using ANN with PI Speed Controller
}

\author{
Suneel Kumar ${ }^{1}$, Pratibha Tiwari ${ }^{2}$ \\ M. Tech (CI), EE, SHIATS, Allahabad, India ${ }^{1}$ \\ Assistant Professor, EE, SHIATS, Allahabad, India ${ }^{2}$
}

\begin{abstract}
In this paper, we proposed a methods of implementation of intelligent controller for speed control of an induction motor using indirect vector control method has been analyzed in detail. Induction motor is used in many industrial applications of the total used electrical energy. This paper proposes a new control scheme based on artificial neural networks to obtain certain torque and speed operating point. The combine performances of PI speed controller and ANN is used with indirect VOC. Due to its simplicity of designing and construction this method is most effective.
\end{abstract}

Keywords: ANN; PI speed controller; intelligent controller; Induction motor; Vector Control method.

\section{INTRODUCTION}

A three phase IM is a singly excited ac machine whose efficiency is at rated speed and load torque is high. Its stator windings receive its energy from stator by mean of induction which is connected through from ac source. Usually, in this method the objectives are achieved by decoupling the direct current-component and quadrature component of IM. Both the stator and rotor produced $\mathrm{mmf}$ wave both rotates in same direction at synchronous speed. The produced mmf are thus stationary but at synchronous speed it is not possible the development of the electromagnetic torque. The PID controller is most commonly used. The main problem of that simple controller is the correct choice of the PID gains and the fact that by using fixed gains, the controller may not provide the required control performance, when there are variations in the plant parameters and operating conditions. Therefore, a tuning process must be performed to insure that the controller can deal with the variations in the plant. To tune the PI controller (usually in drives applications the derivative part of the controller is not used) a lot of strategies have been proposed. The most famous, which is frequently used in industrial applications, is the Ziegler-Nichols method which does not require a system model and control parameters are designed from the plant step response. Tuning using this method is characterized by a good disturbance rejection but on the other hand, the step response has a large percentage overshoot in addition to a high control signal that is required for the adequate performance of the system. Another technique uses frequency response methods to design and tune PI controller gains based on specified phase and gain margins as well as crossover frequency. Furthermore, root locus and pole assignment design techniques are also proposed in addition to transient response specifications. All these methods are considered as model based strategies and then the efficiency of the tuning law depends on the accuracy of the proposed model as well as the assumed conditions with respect to actual operating conditions. Artificial Intelligence (AI) techniques such as neural networks, fuzzy logic and Genetic algorithms are gaining increased interest nowadays.

A lot of techniques have been proposed to tune the gains of PI controller based on AI techniques: neural network techniques is one of these methods proposed for the online adaptive tuning of PI controller. In such application, the controller gains are tuned with the variation of system conditions. The combinations of AI techniques are introduced such as neural network. The advantage of these techniques is that they are model free strategies because they use the human experience for the generation of the tuning law [1]. This paper provides a comparison between two strategies used for tuning the PI speed controller in the Indirect Vector controlled induction motor. The first one is based on Artificial Intelligence while the second one is based on vector control method with simple PI controller.

\section{VECTOR CONTROL OF IndUCTION MOTOR}

The Vector Oriented Controller (VOC) is also known as Field Oriented Controller (FOC). The main objective of this control method is to independently control the torque and the flux as in induction machines. This is done by choosing a d-q rotating references frame synchronously with the rotor flux space vector. Once the orientation is correctly achieved, the torque is controlled by the torque producing current which is the q-component of the stator current space vector. At the same time, the flux is controlled by the flux producing current, which is the dcomponent of the stator current space vector. Indirect field-oriented control, both the instantaneous magnitude and position of the rotor flux are supposed to be precisely known. Crucial to the success of this well known control technique is a priori knowledge of the rotor electrical term constant which varies with temperature, frequency and saturation. This method of induction machine achieves decoupled torque and flux dynamics. This is achieved by orthogonal projection of the stator current into a torqueproducing component and flux-producing component. This technique is performed by two basic methods. Direct and indirect vector control. With direct field orientation, the instantaneous value of the flux is required and obtained by direct measurement using flux sensors or flux estimators, whereas indirect field orientation is based on the inverse flux model dynamics and there are three possible implementation 
based on the stator, rotor, or air gap flux orientation. The rotor voltage source inverter (VSI) is simpler and can be easily flux indirect vector control technique is the most widely used implemented. Since current control is preferable for high due to its simplicity. FOC methods are attractive but suffer performance drives this is not an obvious choice.

from one major disadvantage. They are sensitive to parameter variations such as rotor time constant and incorrect flux measurement or estimation at low speeds [3], [4]. Basic block diagram of FOC is shown in figure 1 [2].

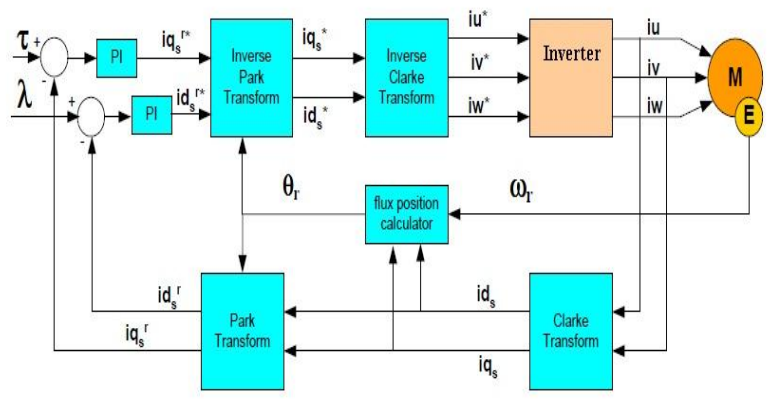

Figure 1 Basic block diagram of VOC

\section{1: Modelling of Vector Control Induction Motor}

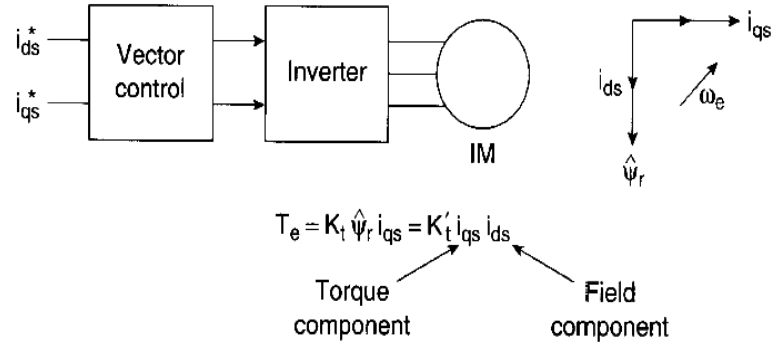

Fig. 2 Vector Control induction motor

As shown in fig. 1 construction of DC machine is such that field flux $\Psi_{\mathrm{f}}$ produced by the field current If is perpendicular to the armature flux $\Psi_{\text {a }}$ produced by the armature current Ia. These are decoupled in nature. This means that torque is individually controlled by the current $\mathrm{I}_{\mathrm{a}}$, without affecting the $\Psi_{\mathrm{f}}$ and we get fast transient response and high torque/ampere ratio with rated $\Psi_{\mathrm{f}}$.

As shown in fig. 2, DC machine-like can also be extended to an induction motor if the machine control is considered in a synchronously rotating reference frame $(d-q)$ where the sinusoidal variables appear as DC quantities in steady state.

There are three ways of vector control based on the reference frame in which the stator currents are transformed. They are:

(1) Stator flux oriented control

(2) Magnetizing flux oriented control

(3) Rotor flux oriented control

\section{(1) Stator Flux Oriented Control}

In stator flux oriented control, the stator quantities are transformed into a reference frame which rotates at the speed of stator flux linkage vector. The rotor current is replaced by:

$$
i_{\mathrm{ms}}=(1+\sigma) i_{\mathrm{s}}+i_{\mathrm{r}} \mathrm{e}^{\mathrm{j} \theta \mathrm{r}}
$$

By this substitution there exists an inherent coupling between flux and torque producing components. Hence, separate decoupling circuits are needed. This delays the control action. The decoupling circuit for voltage controlled

\section{(2) Magnetizing Flux Oriented Control}

In magnetizing flux oriented control, the stator quantities are transformed into a reference frame which rotates at the speed of magnetizing flux linkage vector.

The rotor current is replaced by:

$$
i_{\mathrm{m}}=i_{\mathrm{s}}+i_{\mathrm{r}} \mathrm{e}^{\mathrm{j} \theta \mathrm{r}}
$$

By this substitution, there also exists coupling between flux and torque producing components. The decoupling circuit required for independent control of flux and torque is very complex. Hence, this method is rarely used.

\section{(3) Rotor Flux Oriented Control}

In Rotor Flux Oriented (RFO) control [7], the motor quantities are transformed into a reference frame which rotates at the speed of rotor flux linkage. The rotor current vector is replaced by $i_{\text {mr }}$, which is expressed as:

$$
i_{\mathrm{mr}}=i_{\mathrm{s}}+\left(1+\sigma_{\mathrm{r}}\right) i_{\mathrm{r}} \mathrm{e}^{\mathrm{j} \theta}
$$

Where,

$\mathrm{i}_{\mathrm{mr}}=$ rotor magnetizing current in stationery frame.

$\sigma_{r}=$ the rotor leakage factor

Using the expression for $i_{\mathrm{r}}$ in stationery reference frame is given by:

$$
i_{\mathrm{r}} \mathrm{e}^{\mathrm{j} \theta \mathrm{r}}=\frac{i_{\mathrm{mr}}-i_{\mathrm{s}}}{1+\sigma_{\mathrm{r}}}
$$

The expression for torque becomes:

$$
\mathrm{T}_{\mathrm{e}}=\underline{\mathrm{L}_{\mathrm{m}}^{2} i_{\mathrm{mr}} i_{\mathrm{s}} \sin \delta}
$$

$$
2 \mathrm{~L}_{\mathrm{T}}
$$

Where,

$\delta=$ angle between field frame and rotor frame

The current vectors $i_{\mathrm{s}}$ and $i_{\mathrm{mr}}$ are transformed into a reference frame which rotates at the speed of rotor flux linkage vector. In rotor flux oriented reference frame, the $i_{m r}$ has only $d-$ axis component, which is equal to $i_{\mathrm{mr}}$ (represents the magnitude of imr). The expression for is in rotor field oriented reference frame is given by:

$$
i_{\mathrm{s}} \mathrm{e}^{-\mathrm{jpr}}=i_{\mathrm{sx}}+i_{\mathrm{sy}}
$$

Where,

$\rho r=$ angle between the rotor field reference frame and stationery reference frame.

$\mathrm{i}_{\mathrm{sx}}=\mathrm{d}-$ axis component of stator current in rotor field reference frame.

$\mathrm{i}_{\mathrm{sy}}=\mathrm{q}-$ axis component of stator current in rotor field reference frame. Now the torque equation becomes:

$$
\mathrm{T}_{\mathrm{e}}=\frac{\mathrm{L}^{2}{ }_{\mathrm{mp}} i_{\mathrm{mr}} i_{\mathrm{sy}}}{2 \mathrm{~L}_{\mathrm{r}}}
$$

This equation is similar to that of DC motor's torque equation where $i_{m r}$ is Similar to field current and $i_{\text {sy }}$ similar to armature current of DC motor. 


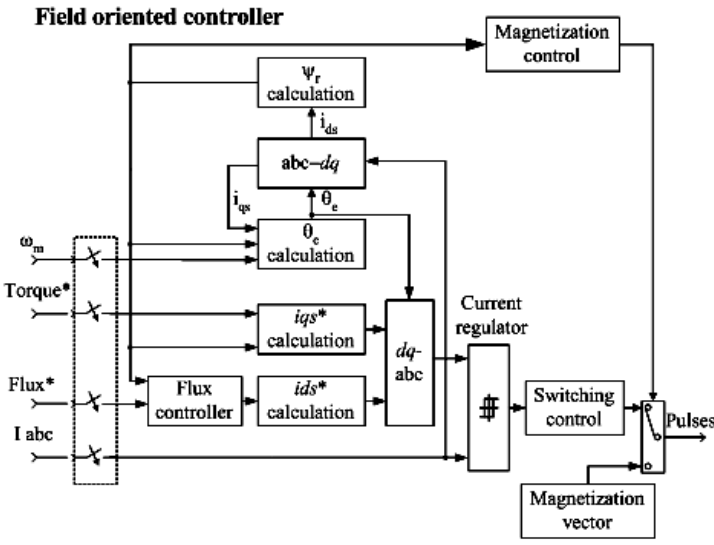

Fig.3 Basic block diagram of FOC.

\section{III.ARTIFICIAL NeURAL NeTWORK}

All Artificial neural networks are relatively crude electronics models based on the neural structure of human brains.ANN is an information processing paradigm that is inspired by the way biological nervous systems like the human brain the ANN can be trained to solve the lost complex non-linear problems. There are several applications of ANN in AC drives such as speed control or energy saver, adaptive speed control, current control .Neural networks can massively performs parallel operations. They are robust in nature i,e; they can still performs its overall function even if some of the neurons are not functioning. NN have two inputs, motor torque and speed and have two outputs, optimum voltage and frequency.

In this paper, two layer feed forward structure of $\mathrm{NN}$ model which has two hidden layer. We preferred the tansigmoid function and other is of pure linear function since the optimum voltage and frequency are highly non-linear function and other is of pure linear function. The inputs of the ANN are feed to the layer of tan sigmiodal function and output of this layer is broadcast to the layer of linear neurons.

\section{1: Neural Architecture}

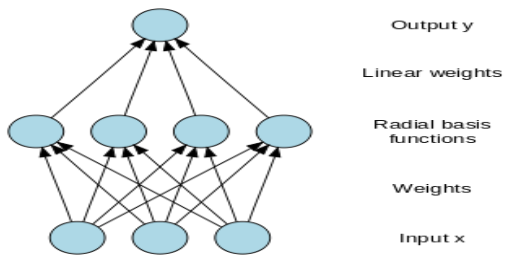

Figure 1: Architecture of a radial basis function network An input vector $\mathbf{x}$ is used as input to all radial basis functions, each with different parameters. The output of the network is a linear combination of the outputs from radial basis functions. Radial basis function (RBF) networks typically have three layers: an input layer, a hidden layer with a non-linear RBF activation function and a linear output layer.

\section{2: Algorithm}

First the input is given to the input layer.

$>\quad$ The network is simulated and initialized. For deciding the number of neurons in hidden

$>\quad$ Layer k-means algorithm is used.
Iterate until the network converges.

$>\quad$ Calculate the error between the network's o/p \& the target $\mathrm{o} / \mathrm{p}$. if the error isn't in the desired limit go to step 3 else go to step 5 .

$>\quad$ Observe the performance of the network with the training and the test data. Re-train if necessary.

\section{3: K - means Algorithm}

$>\quad$ Choose initial centres c1... ck.

$>\quad$ While the clusters are changing, repeat step 3 to

4.

Assign data point pi to the cluster whose centre C

is closest. This can be done by using

$>\quad$ Euclidean distance.

$>\quad$ Update the cluster centres given by :-

> $\mathrm{C}=(1 / \mathrm{n}) \Delta \mathrm{P}$. $\mathrm{n}=$ number of points in $\mathrm{C}$

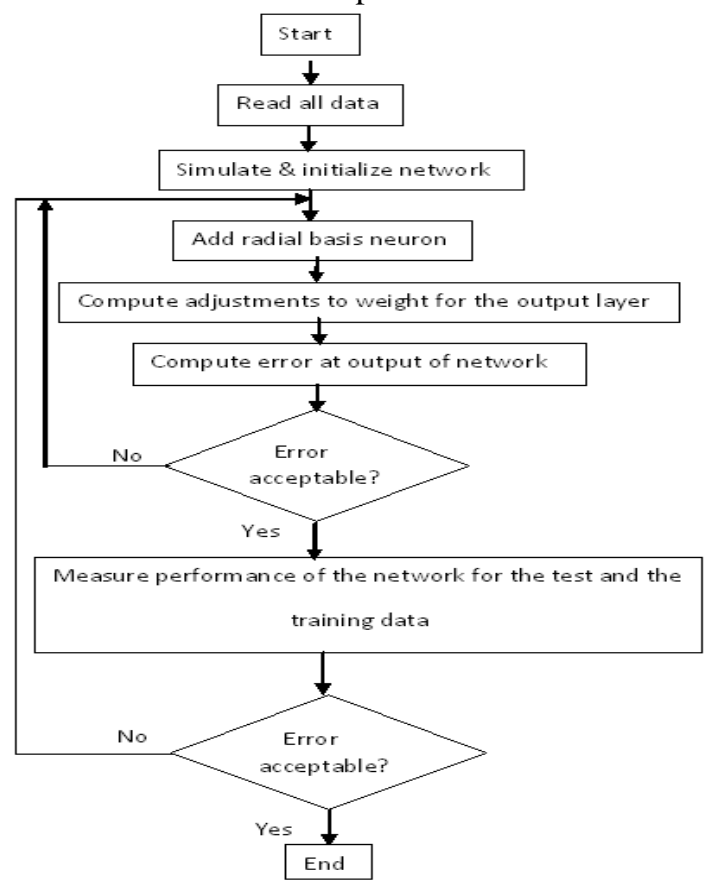

Figure 4. Flowchart of RBF neural network

\section{IV.PI CONTROLLER}

The PI controller has been introduced in process control industries. The controller responds to an error signal in a close control loop and it adjust the controlled quantity to achieve the desired system response. The benefits of the PI controller are that it can be adjusted empirically by adjusting one or more gain values. The controlled parameter can be any measurable systems such as speed, torque or flux. The sign of the error indicates that the direction of change required by the control inputs. The integral (I) term of the controller can be used to eliminate small steady states errors, it also calculates the continuous running total of the error signal. Then this accumuted error signal is then multiplied by an I gain factor and it becomes the I output terms or the PI controller.

4.1: Tuning of the PI Controller- The tuning is the technique that is adopted for determining the proportional integral constants of the controller. Tuning depends upon the dynamics response of the plants.

\footnotetext{
Copyight to IJIREICE
}

\begin{abstract}
(D.
\end{abstract}


INTERNATIONAL JOURNAL OF INNOVATIVE RESEARCH IN ELECTRICAL, ELECTRONICS, INSTRUMENTATION AND CONTROL ENGINEERING Vol. 3, Issue 3, March 2015

4.1.1: Zeigler- Nichols Rules for tuning PI controllers: The $S$-shaped response is characterized by two constants, the dead time $L$ and the time constant $T$ as shown. These constants can be determined by drawing a tangent to the $S$ shaped curve at the inflection point and state value of the output. From the response of this nature the plant can be mathematically modelled as first order system with a time constant $T$ and delay time $L$ as shown in block diagram [9]. The gain $K$ corresponds to the steady state value of the output Css. The value of $\mathrm{Kp}, \mathrm{Ti}$ and $\mathrm{Td}$ of the controllers can then be calculated as below:

$$
\mathrm{Kp}=1.2(\mathrm{~T} / \mathrm{L})
$$

$$
\tau \mathrm{i}=2 \mathrm{~L}
$$

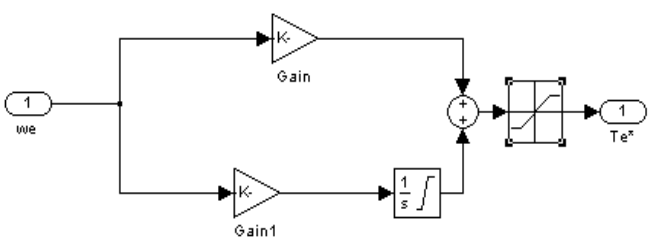

Fig 2.3 PI Controller 1st order system block diagram.

\section{Simulation \& Result}

A three-phase induction motor rated at $50 \mathrm{hp}, 460 \mathrm{~V}$, 4pole, $50 \mathrm{~Hz}$ is modelled in the common stator reference frame. The speed loop utilizes a PI controller to produce the quadrature-axis currents iq* which serves as the torque command. The derived direct-axis current id* serves as the rotor flux command. These currents are then transformed via the dq to abc block into the current references ia*, ib*, and ic* fed into the current regulator. The currentcontrolled PWM inverter is made up of three hysteresis controllers. Rotor flux field orientation is obtained in the theta calculator block.

The machine is initially operating in steady state at no load $(\mathrm{Tl}=0)$ at the speed wref=120rad/s. Examine the transient response due to step changes in the command speed wref and load torque Tl. Repeat the simulation for a so-called detuned case when the estimated value of the rotor time constant $\mathrm{Tr}$ appearing in the theta calculator differs from the actual value used for the motor parameters.

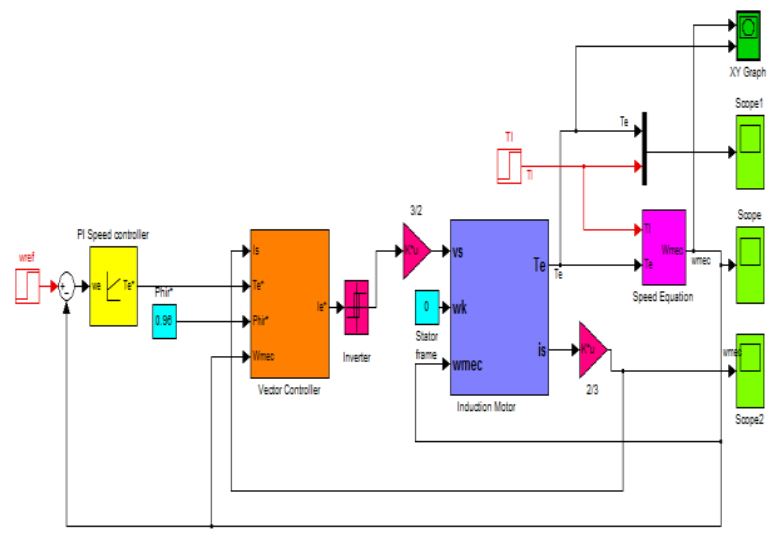

Figure 5.1; Indirect Vector Control of Induction Motor using ANN with PI Speed Controller

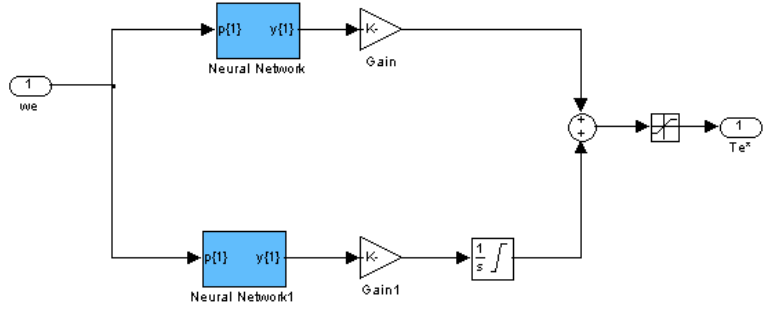

Fig 5.2: ANN Controller 1st order system

For the analysis purpose the Four condition has been taken

Condition $\mathrm{I}-\mathrm{At} \mathrm{Tl}=100 \& \omega \mathrm{s}=120 \mathrm{rad} / \mathrm{sec}$

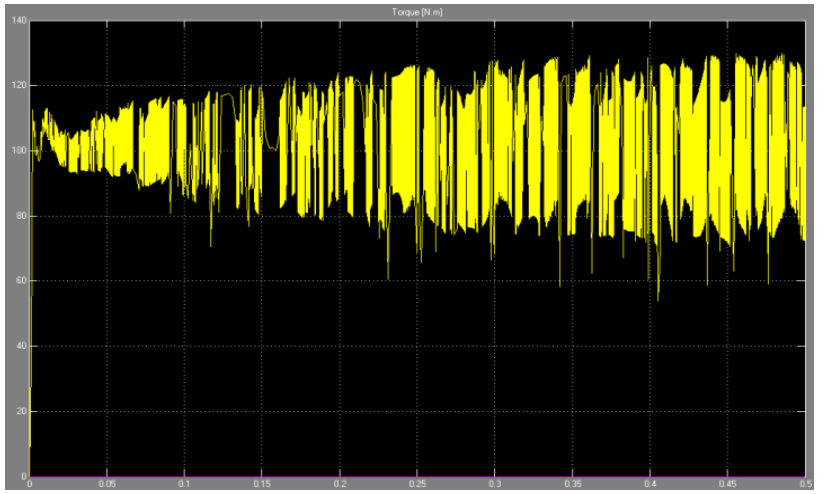

Fig 5.3: Torque of $\mathrm{IM}$ at $\mathrm{Tl}=100 \mathrm{~N}-\mathrm{m}$

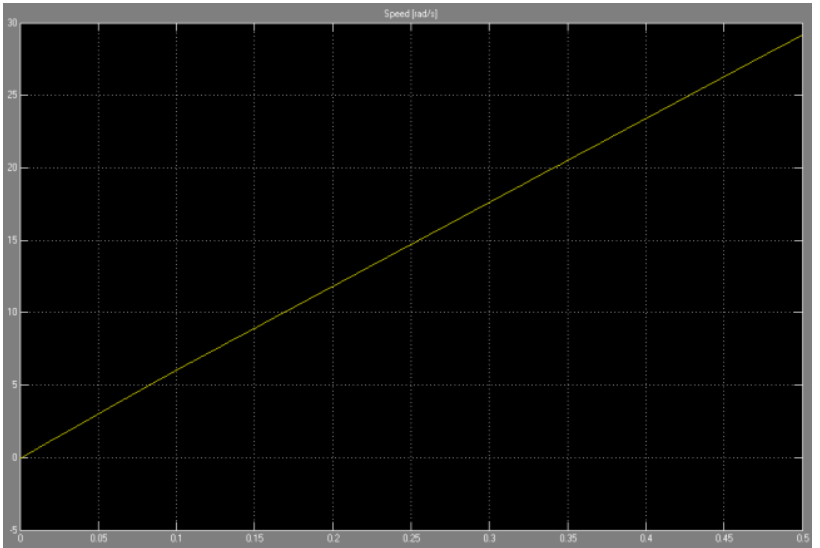

Fig 5.4: Speed of IM at $\mathrm{Tl}=100 \mathrm{~N}-\mathrm{m}$

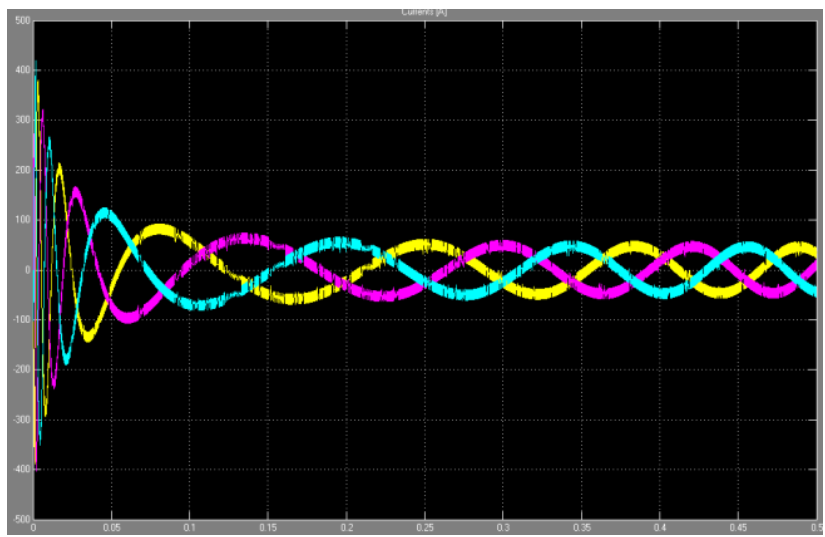

Fig 5.5: Current waveform of IM at $\mathrm{Tl}=100 \mathrm{~N}-\mathrm{m}$ 
INTERNATIONAL JOURNAL OFINNOVATIVE RESEARCH IN ELECTRICAL, ELECTRONICS, INSTRUMENTATION AND CONTROL ENGINEERING Vol. 3, Issue 3, March 2015

Condition II - At $\mathrm{Tl}=200 \& \omega \mathrm{s}=120 \mathrm{rad} / \mathrm{sec}$
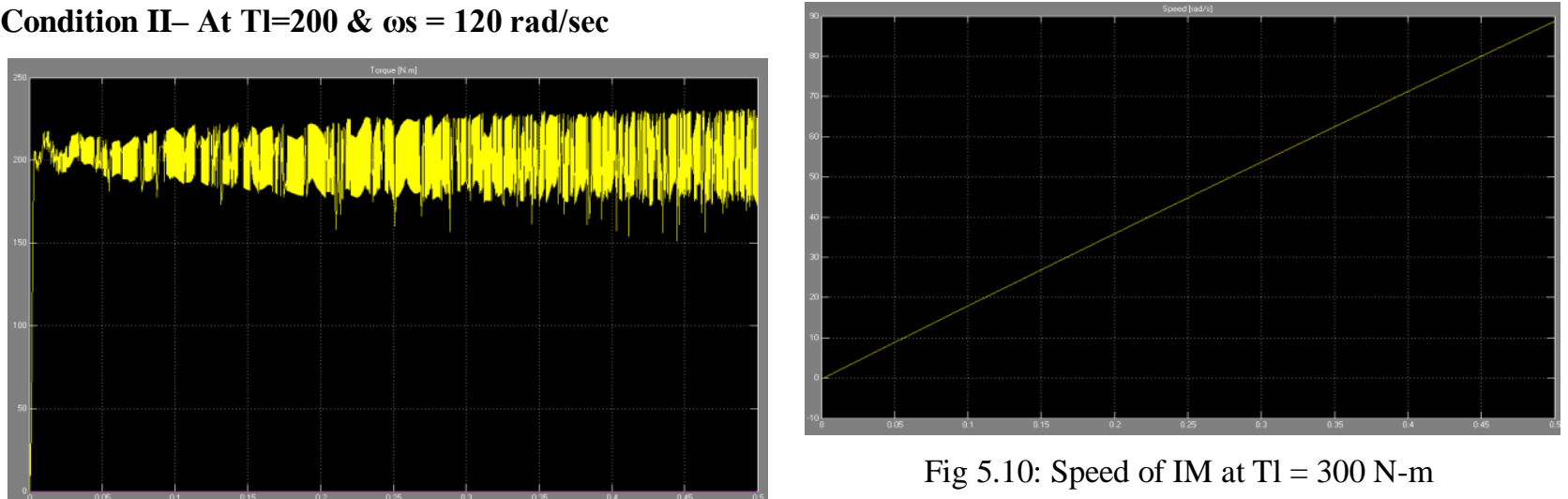

Fig 5.10: Speed of IM at $\mathrm{Tl}=300 \mathrm{~N}-\mathrm{m}$

Fig 5.6: Torque of IM at $\mathrm{Tl}=200 \mathrm{~N}-\mathrm{m}$
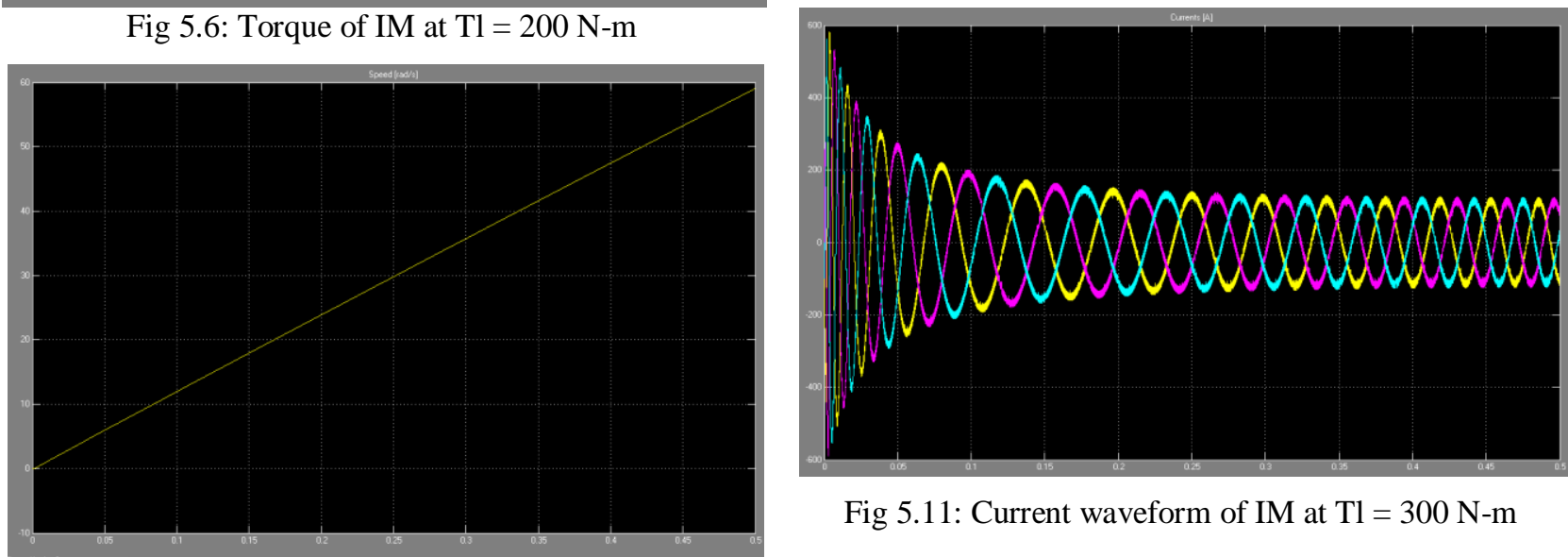

Fig 5.11: Current waveform of IM at $\mathrm{Tl}=300 \mathrm{~N}-\mathrm{m}$

Fig 5.7: Speed of IM at $\mathrm{Tl}=200 \mathrm{~N}-\mathrm{m}$

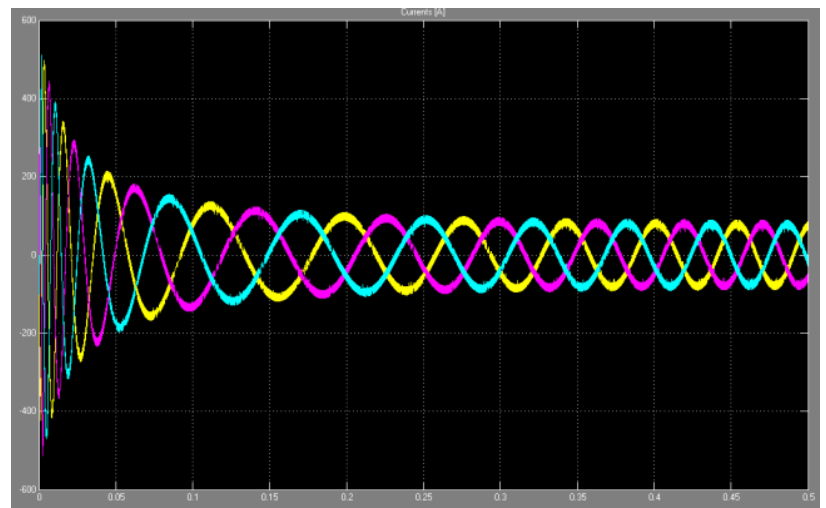

Fig 5.8: Current waveform of $\mathrm{IM}$ at $\mathrm{Tl}=200 \mathrm{~N}-\mathrm{m}$

Condition III - At $\mathrm{Tl}=300 \& \omega \mathrm{s}=120 \mathrm{rad} / \mathrm{sec}$

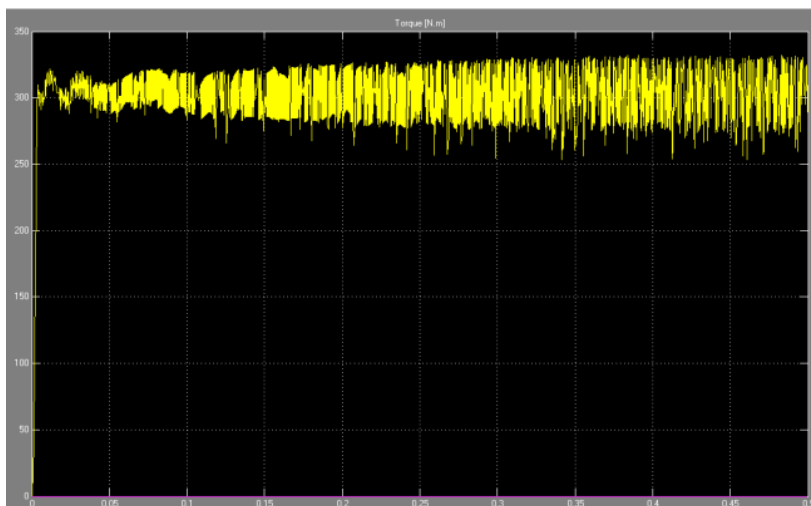

Condition IV - At $\mathrm{Tl}=0$ \& $\omega \mathrm{S}=120 \mathrm{rad} / \mathrm{sec}$

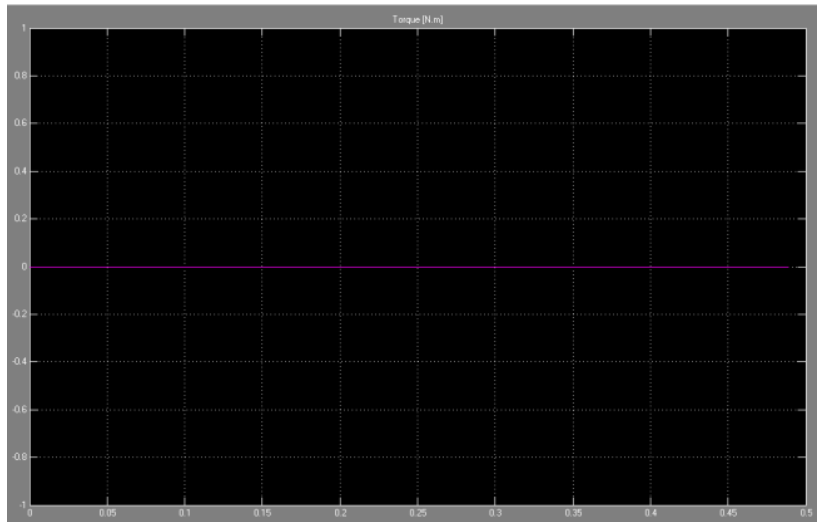

Fig 5.12: Torque of IM at $\mathrm{Tl}=0 \mathrm{~N}-\mathrm{m}$

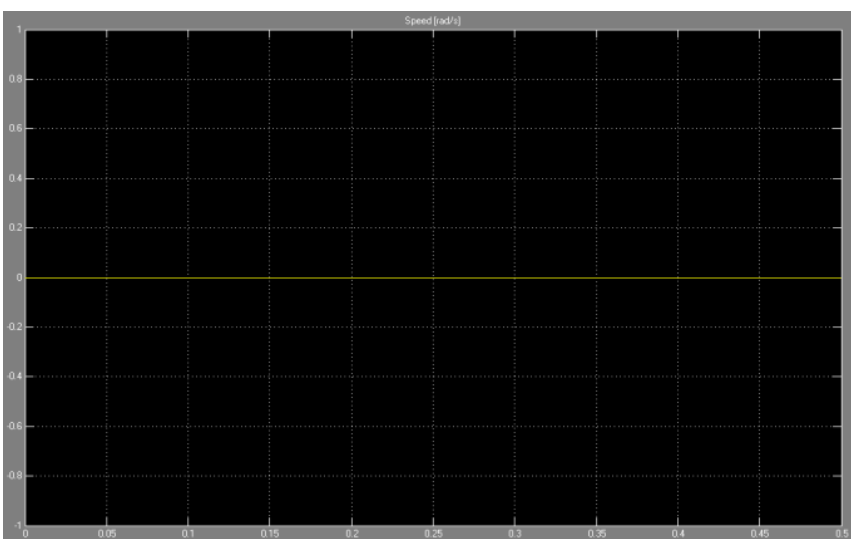

Fig 5.13 : Speed of IM at $\mathrm{Tl}=0 \mathrm{~N}-\mathrm{m}$

Fig 5.9: Torque of $\mathrm{IM}$ at $\mathrm{Tl}=300 \mathrm{~N}-\mathrm{m}$ 


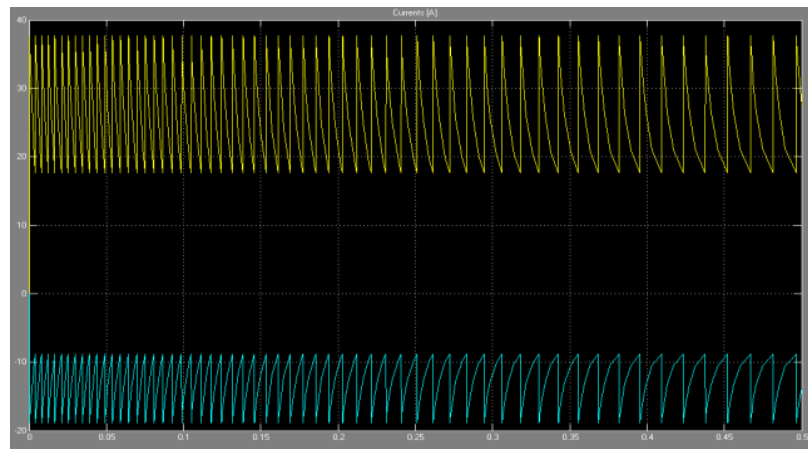

Fig 5.14: Current waveform of $\mathrm{IM}$ at $\mathrm{Tl}=0 \mathrm{~N}-\mathrm{m}$

The performance of IM shows different variation at different $\mathrm{Tl}$ and speed condition in all result.

\section{CONCLUSION}

This project has been successfully demonstrated and PI controller and Artificial Neural Network is properly designed. We have studied and combined two controllers for speed control of indirect vector control induction motor drive. At given result and their data of induction motor current, motor torque, and speed at no load and $100,200,300 \mathrm{~N}-\mathrm{m}$ load performances are examined. In future with the help of other controller, methods, Model Reference Control induction motor drives (VCIMDs) can be better controlled.

\section{REFERENCES}

1. Shady M. Gadoue, D. Giaouris and J. W. Finch; Induction Motor Based on Genetic Algorithms and Fuzzy Logic Schemes;

2. Uthra.R et al. "Neural network based vector control of induction motor" DOI : 10.5121/csit.2013.3409

3. C. Mohan Krishna et al. "Indirect vector control of induction motor using Pi Speed controller and neural networks" (IJMER) Vol.3, Issue.4, Jul - Aug. 2013 pp-1980-1987

4. Woodley, K.M., Li, H., Foo, S.Y.: Neural Network modeling of Torque Estimation and d-q Transformation for Induction Machine. Eng. Appl. of Artif. In tell. 18(1), 57-63 (2005)

5. C.M.Liaw. Y.S.Kung and M.S.Ouyang Identification and control of induction machines using artificial neural networks. IEEE Trans Ind.Applicat. Vol.31.pp.612-619, 1995.

6. H.A.Al-Rashidi, A.Gastli, A.Al-Badi, "Optimization of Variable Speed Induction Motor Efficiency Using Artificial Neural Network".

7. M. N, et al, Neural and Fuzzy Logic Control of Drives and Power Systems, Linacre House,Jordan Hill, Oxford OX2 8DP. 2002

8. Joachim Holtz, Sensorless Control of Induction Motor Drives, Proc. Of IEEE, Vol. 90, No. 8, Aug. 2002.

9. Kheldoun Aissa, and Khodja Djalal Eddine, “ Vector Control Using Series Iron Loss Model of Induction, Motors and Power Loss Minimization" World Academy of Science, Engineering

10. A. Miloudi and A. Draou "Variable Gain PI Controller Design For Speed Control and Rotor Resistance Estimation of an Indirect Vector Controlled Induction Machine Drive " Conference Record of the IECON '02 Sevilla, Spain, Vol. 1, pp. 323-328, Nov 2002.

11. Adel Merabet, Mohand Ouhrouche and Rung-Tien Bui," Neural Generalized Predictive Controller for Induction Motor". Volume 1 Number 1 pp. 83-100, University of Quebec at Chicoutimi.2006

12. K. S. Narendra and K. Parthasarathy, "Identification and control of dynamic systems using neural networks," IEEE Trans. Neural Networks, vol.1, pp.4-27, Jan.1990.

13. Seyed Hossein HOSSEINIand Mohamad Reza BANAEI " Neural network speed controller for induction motor based on feedback linearization".

14. Jianrong $\mathrm{Bu}$, Longya $\mathrm{Xu}$, "A High Performance Full Fuzzy Controller for Induction Machine Drives”, IEEE APEC Conf., Vol. 2, pp. 592-596, 1998.

15. P. Vas, and J. Li, "Simulation Package for Vector Controlled Induction Motor Drives", Oxford University press, 1993.

Copyright to IJIREEICE

Suneel Kumar Belong to UP Received his Bachelor of Technology degree from SIET UP Technical University, Allahabad in 2013. He is pursuing his M.Tech in Electrical Engg. (Control \& Instr) from SHIATS, Allahabad, UP-India.

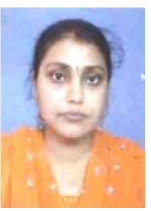

Pratibha Tiwari presently working as Assistant Professor in Electrical Engineering at Sam Higginbottom Institute of Agriculture Technology \& Sciences, Allahabad, (U.P) India.

The degree of B.Tech secured in Electrical \& Electronics Eng. from UCER, Allahabad in 2002 and M.Tech. in Control and Instrumentation from MNNIT, Allahabad in 2006. Research interest includes Control \& Instr. and Power Electronics 